\title{
Teaching Social Media in Business
}

\author{
Roger McHaney \\ Kansas State University, \\ Manhattan, KS, USA \\ mchaney@ksu.edu \\ David Sachs \\ Pace University, \\ White Plains, NY, USA \\ dsachs@pace.edu
}

\author{
Merrill Warkentin \\ Mississippi State University, \\ Mississippi State, MS, USA \\ m.warkentin@msstate.edu
}

\author{
Michael Brian Pope \\ Mississippi State University, \\ Mississippi State, MS, USA \\ mpope5678@gmail.com
}

\section{Dustin Ormond Creighton University, Omaha, NE, USA \\ dustinormond@creighton.edu}

\begin{abstract}
The ways people connect, interact, share, and communicate have changed due to recent developments in information technology. These developments, categorized as social media, have captured the attention of business executives, technologists, and education professionals alike, and have altered many business models. Additionally, the concept of social media impacts numerous sub-disciplines within business and has become an important issue with operational, tactical, and strategic considerations. Despite this interest, many business schools do not have courses involving social media technologies and applications. In those that do, the placement and focus of the course varies considerably. This article provides motivation and insight into the process of developing an approach for effectively teaching social media use in business. Additionally, it offers implementation examples of courses taught at three major universities. The article concludes with lessons-learned that will give instructors practical guidance and ensure that social media courses taught in a business school provide students with a solid basis for integrating social media into business practice.
\end{abstract}

Material published as part of this publication, either on-line or in print, is copyrighted by the Informing Science Institute. Permission to make digital or paper copy of part or all of these works for personal or classroom use is granted without fee provided that the copies are not made or distributed for profit or commercial advantage AND that copies 1) bear this notice in full and 2) give the full citation on the first page. It is permissible to abstract these works so long as credit is given. To copy in all other cases or to republish or to post on a server or to redistribute to lists requires specific permission and payment of a fee. Contact Publisher@,InformingScience.org to request redistribution permission.
Keywords: social media, teaching, higher education, business education, course development.

\section{Introduction}

A revolution has crept up on the business world and dramatically altered the way people connect, interact, share, communicate, and even think. The speed with which social media has permeated social and economic practices was rela-

Editor: Minh Huynh

Submitted: November 18, 2014; Revised: February 17, 2015; Accepted: March 12, 2015 
tively unexpected and not clearly on the radar screen of many futurists (Aburdene, 2005). However, measures of social media use continue to soar. The Nielsen Company (2012) suggests that social media and social networking are maturing as they evolve and "offer consumers around the world new and meaningful ways to engage with the people, events, and brands that matter to them." They also suggest more growth lies ahead, and this phenomenon is global. For these reasons, business education programs must effectively integrate social media concepts and practices into numerous sub-disciplines. Despite the apparent impact, few business schools have integrated social media into programs of study. In those that do offer courses, placement and focus vary considerably.

The primary goal of this article is to provide both motivating factors and practical implementation suggestions for teaching social media in a business school. First, a context for the study is provided to include information about the advent and importance of social media. Next, we review challenges to educators working in this area. Then, a review of existing social media course approaches is provided. Following this general investigation, we offer an approach for teaching social media with attention paid to Bloom's taxonomy adapted to social network environments and to accreditation concerns. Next, we provide practical insight regarding the implementation of social media courses using specific examples from three major U.S. universities. The article concludes with student feedback and instructors' observations in the form of lessons-learned that can be used to jump-start social media teaching efforts.

\section{Study Context}

\section{Challenge to Educators}

In July of 2011 a total of 88.4 billion minutes were spent on social media. One year later that total was up to 121.1 billion minutes (Nielsen Company, 2012). According to Pew Research, $67 \%$ of Internet users engage in social media (Duggan \& Brenner, 2013). Social media use is not limited to personal applications. In fact, business practices are changing dramatically as more companies become part of the social media fabric and choose to use tools provided by Facebook, LinkedIn, Pinterest, Twitter, and others to interact with customers, potential customers, and other stakeholders.

Though social media use offers great promise for business futures, it also poses one of the most significant challenges to educators in recent years. Understanding social media and its application to achieve organizational goals is critical knowledge for the modern business student, in part because it has dramatically changed both student (Junco, 2012, 2013) and consumer behavior (Harris \& Rea, 2009). As broader age groups become savvy social media users, the impact promises to be even greater (Buzzetto-More, 2012). Nearly every aspect of business is affected; transaction processing, marketing, recruitment, customer service, account management, and many other areas are challenged to rethink approaches. This further points out the need for business schools to incorporate changes into their curricula.

Changing population characteristics also have contributed to this challenge. Many people born between 1980 and 1994 belong to the first generation to be raised "with the Internet." These people, often called Tech Savvy Millennials (Huhman, 2013) or the digital generation (Buzzard, Crittenden, Crittenden, \& McCarty, 2011), have a different set of expectations than their predecessors. They expect to have readily available information on all topics at all times. They are accustomed to personalizing, customizing, and having the freedom to control information they consume (Thoms, 2012). This makes them, on the whole, a group of consumers less likely to tolerate invasive marketing tools, such as television ads and direct marketing calls, accepted by earlier generations. 
Modern business leaders are aware of how quickly social media has permeated the social fabric and have begun to experiment with advantageous use of it. Social media generally permit the identification of new customers and a continuing relationship with existing customers. It also allows information relevant to both potential and current customers to be gathered (Kietzmann, Hermkens, McCarthy, \& Silvestre, 2011). New venues for business interaction are also available. For instance, a business can build a fan base and receive substantial feedback from targeted individuals. Businesses can mine unstructured social media data as a means to acquire and fine tune business intelligence. Since much of the data on social media is public, information about competitors and competing products can also be obtained. Causal and recreational social media use has developed into a venue for transforming an audience into customers and for transforming customers into loyal advocates.

The current technology-enabled shift in business practices has created a priority for educators. Additionally, there is a growing need to facilitate business students in the exploration, understanding, and integration of social media practices into their areas of domain expertise (Jeffrey et al., 2011; Magro, Sharp, Ryan, \& Ryan, 2013). Media attention, student expectations, academicians (Brightman \& Nargundkar, 2013), and advisory board pressure have all drawn attention to the need for social media education. Businesses hiring university graduates often expect a level of competency and literacy with new technologies and this has impacted the immediacy of including social media issues in course topics (Levy \& Hadar, 2010).

Using another perspective, continued accreditation of high quality business programs must consider evolving technologies. For instance, the Association to Advance Collegiate Schools of Business (AACSB) accreditation standards requires attention to information technology either in the form of specific courses or some other learning experience in the core curriculum. Specifically, Standard 15 of the AACSB (2013) states: "Management of Curricula: The school uses welldocumented, systematic processes to develop, monitor, evaluate, and revise the substance and delivery of the curricula of degree programs and to assess the impact of the curricula on learning. Curriculum management includes inputs from all appropriate constituencies which may include faculty, staff, administrators, students, faculty from non-business disciplines, alumni, and the business community served by the school." Though the standard requires a systematic process for curriculum management, it does not mandate any specific courses. However, the published standard suggests that the approved courses will cover skill areas such as the use of information technology. The authors further suggest that such coverage will include IT "as they influence the structure and processes of organizations and economies, and as they influence the roles and techniques of management."

The current impact of social media and Web 2.0 technologies certainly has this influence and, as such, becomes an important element for consideration as future programs of study and curricula are developed in universities.

\section{Teaching Social Media in Business Colleges}

As described earlier, social media play an important role in society and in business operations, tactics, and strategies. Approaches to marketing, customer behaviors, decision-making, and numerous other areas have been significantly impacted; therefore, it is important to consider social media's impact in a variety of ways (Shim, Dekleva, Guo, \& Mittleman, 2011).

From an education standpoint several approaches to teaching/learning are possible (Chao, Parker, $\&$ Fontana, 2011). One approach is to make theoretical material the sole focus of social media and Web 2.0 courses. While this would provide good information to the students, it could take a subject inclined towards hands-on participation and remove important practical elements. Like- 
wise, education efforts can focus on applications and miss the big picture, theoretical origins, and underlying reasons for social media use.

Another approach is to sprinkle social media into existing courses as enrichment. In fact, many educators are experimenting with this idea (Deans, 2012; Halvorson, Crittenden, \& Pitt, 2011) and have published a plethora of studies integrating social media as instructional devices (Bahner et al., 2012). This approach is consistent with literature suggesting that e-learning improvements are linked to relevant teaching technique changes (Sulčič \& Lesjak, 2009). However, teaching in this manner may fail to prepare students with an appropriate depth of knowledge for business use.

It makes sense to integrate social media practices that draw on student experiences from their daily lives (Sacks \& Graves, 2012). However, the problem with such integration is that, without a foundation of knowledge, the discussion can seldom move beyond a surface treatment. In other words, integration makes students aware of various technologies but may not equip them with deeper skills required to address and confront long-term business issues. Additionally, students may begin to believe that social media use for business is casual and involves little more than a surface level deployment to be effective. This sort of thinking is currently reflected in many organizations. Hanna, Rohm, and Crittenden (2011) suggest that many companies recognize the need to have a social media presence, but many "do not truly understand how to do it effectively, what performance indicators they should be measuring, and how they should measure them." Potential public relations disasters may also befall a company that does not understand how to appropriately use social media. A single ill-timed or ill-formed tweet or posting may be remembered for years, and in some cases may be more memorable to the public than the company's actual business.

Added to the conundrum is the fact that many educators feel ill-equipped to teach social media practices. They may feel overwhelmed by the volume of social media software, tools, approaches, and techniques. Many educators feel students might know far more than they do in this area (Kelm, 2011; Morgan, 2012). However, some studies find that while this is a perception, it may not be true and that students often use social media in their private lives but not so much in education settings (Thomas \& Thomas, 2012). Hrastinski and Aghaee (2012) found that the students they interviewed use social media in their own private lives, yet are critical of its use in education, suggesting it may lead to decreased critical human interaction. Some of their informants felt that "social media is reducing spontaneous interaction and student collaboration," which hindered collaborative learning. They also wondered if reliance on social media and other online resources might suppress their critical sense of discernment.

\section{A General Examination of Social Media Curricula}

Social media is a relatively new Internet phenomenon, and new forms of technology are subject to fads that quickly wane. As such, a professor might question the wisdom of including a topic that they may believe to be highly transitory. However, AACSB guidelines require coverage of IT topics that influence the structure and processes of organizations and economies. As social media could be considered under that requirement, we considered it prudent to examine how many universities were willing to expend significant resources to bolster social media instruction. In particular, it would help determine whether the suggestions in this article - and, further, social media curricula in general - are worth implementing. To this end, we conducted a study on AACSB accredited schools.

We began by examining publicly available course information from institutions listed on the AACSB accreditation website. We searched primarily departments related to information systems and computing disciplines, such as management information systems, computer information systems, computer science, and computer information science. This research focused on undergradu- 
ate courses and ensured that content covered salient topics. We found related graduate courses that were more specialized and fell into niche areas. We avoided experimental courses, focusing on programs offering social media-centric instruction on a consistent basis by using catalog descriptions or the closest readily available analog from the university's Web site. We considered these items as evidence of a long-term commitment to social media-oriented material in the curriculum as catalog entries tend to be more laborious to amend or update than, for example, syllabi.

The data collection process followed a procedure similar to one conducted by Lee (2008). Lee suggested a list of course prefixes discovered during an examination of AACSB accredited universities for the collection process. Several additional prefixes were also added to the search. We collected candidate course descriptions and titles from university Web sites and scanned for the specific phrases "social media," "social network," "social networking," and "Web 2.0." We examined descriptions with matching words in greater detail to determine if the course featured one or more substantial aspects of social media as a major portion or main focus of the coursework. We also made other exceptions. For example, one course unambiguously covered social media, but used "Facebook" as an analog in the description.

Catalogs or text derived from catalogs were generally used to determine the inclusion of social media in coursework. Mentioning these subjects in the catalog illustrates faculty have put in time and effort to commit themselves to delivering this material on an ongoing basis as opposed to offering transitory courses and incidental inclusion in existing courses. It also serves to standardize the delivery of social media across all sections of a course, something that otherwise may fall to the personal discretion of an instructor. Furthermore, the catalog was readily available on most websites, whereas additional course materials are often kept behind courseware or password protection, or may not be on the Internet at all. Using the catalog where possible helped standardize our information sources. Only undergraduate courses were used. This is because graduate courses, by the dynamic nature of graduate work and research, may change more frequently and readily at many universities.

A total of 130 randomly-selected English-speaking AACSB accredited business programs with English Web sites and undergraduate coursework were sampled. Findings from this study included:

- $25(19.23 \%)$ programs included one or more courses with descriptions indicating strong social media or social networking content, mostly regarding IS-oriented curriculum other than its design and programming.

- 4 programs included courses with descriptions strongly suggesting considerable social media content, including data mining, analysis or programming, bringing this figure up to a total of $29(22.31 \%)$.

- $8(6.15 \%)$ programs included one or more courses with descriptions indicating strong IS-oriented Web 2.0 content.

- 4 programs included one or more courses with descriptions indicating strong Web 2.0 programming content, bringing this figure up to a total of $12(9.23 \%)$.

- Although not specifically sampled, at least 28 (21.54\%) programs included social media coursework involving other departments, such as marketing and communications.

Universities are expected to include material on new technology. The search attempted to eliminate ambiguity, did not include experimental courses nor those including content not specifically described in catalog information, and relied on specific keywords (Lee, 2008). Therefore, it po- 
tentially omits courses that have amorphously-worded descriptions which may include social media or social networking content. It may also omit courses that make references to specific Web sites or programs, but no reference to generally accepted terms, such as a course that merely mentions a Web site in its description. This is particularly so if it references sites that are particularly obscure or have shut down. Therefore, the true number of offerings could be greater. However, the findings indicate a reasonable level of teaching social media has emerged in the instructional realm.

\section{Other Findings: Social Media Minor}

One university we investigated during the background research phase offered a social media minor. Although no specific social media courses were listed, this program had enough relevant coursework to warrant a minor. This makes it highly probable that social media material has been diffused throughout several courses to form this option. This approach also may be used in a number of other programs that may not explicitly mention social media-related coursework in their class descriptions. It is worth considering the scholastic aspects of social media not just as a discrete subject, but as a diffuse topic integrated into existing topics and courses.

\section{Social Media in Departments Other than IS}

The background investigation also uncovered findings regarding the proliferation of social mediarelated instruction in alternate departments, such as marketing and communication. Information systems are only one of many disciplines interested in social media. In fact, social media teaching appears to be widely spread in marketing, non-business fields such as journalism and communication, and even areas such as human ecology. These findings raise questions such as: How do IS academics form productive partnerships with alternate disciplines in order to introduce the larger technological and sociological implications of social media to these audiences, while making certain to emphasize those aspects most relevant to their areas of study and work?

The background investigation also noted that, while social media can be taught in separate courses, it does not inherently require such treatment. It may be diffused throughout an educational program both in terms of general theory as well as practice applicable to particular uses. As such, given its high levels of proliferation into ordinary life, it is entirely possible that social media has become more pervasive in the programs of many disciplines without mention in the catalog, course description, or, in some cases, even the syllabus.

\section{Web 2.0 Terminology}

The treatment of the term Web 2.0 is another area of interest that yielded information during the background investigation of university offerings in social media. Web 2.0 is a descriptor used to illustrate a fundamentally different and socially-based way of applying Internet technologies. Web 2.0 is not a specific technical update of underlying software or hardware systems but rather a conceptual change in the way the Web is being used and re-created by businesses, universities, and society. The 2004 O'Reilly Media Web 2.0 Conference coined the term Web 2.0 and this term gained popularity as a way to describe applications that allow people to participate in information creation, digital resource sharing, data classification, social interaction, and automated search (O’Reilly, 2005).

Web 2.0 has been described in a variety of ways from a component standpoint. Part of the reason for this can be attributed to rapidly evolving technologies and emerging application areas. In general, Web 2.0 applications fall into four major interrelated overlapping components: social media, content sharing, filtering and recommendations, and Web applications (McHaney, 2013). These 
components share common core characteristics. Professor Andrew McAfee (2006) of Harvard Business School uses the acronym SLATES to describe these commonalities (see Table 1).

Table 1: SLATES: Common characteristics of Web 2.0 components

\begin{tabular}{|l|l|}
\hline Category & Description \\
\hline Search & Finding information through keyword search. \\
\hline Links & $\begin{array}{l}\text { Connects information into a meaningful ecosystem using the model of the Web and pro- } \\
\text { vides low-barrier social tools. }\end{array}$ \\
\hline Authoring & The ability to create and update content leads to the collaborative work of multiple authors. \\
\hline Tags & $\begin{array}{l}\text { Users categorize content by adding their own descriptive tags, which are short, one or two } \\
\text { word descriptions. Tags facilitate searching based on what Website users believe the sites } \\
\text { represent rather than by capturing developers' views. Collections of tags created by multi- } \\
\text { ple users are called folksonomies (short for folk taxonomies). }\end{array}$ \\
\hline Extensions & $\begin{array}{l}\text { Extension software provides additional capabilities to Web browsers and allows more than } \\
\text { just HTML documents to be used. It essentially makes the Web an application platform as } \\
\text { well as a document server. }\end{array}$ \\
\hline Signals & $\begin{array}{l}\text { Syndication technology enables material to be broadcast to multiple Websites and to notify } \\
\text { consumers when new material appears. }\end{array}$ \\
\hline
\end{tabular}

After a period of popularity, Tim Berners-Lee, World Wide Web inventor, challenged the term Web 2.0 and suggested it is a piece of jargon because the Web is operating the way he had originally envisioned (Berners-Lee, Cailliau, Luotonen, Nielsen, \& Secret, 1994). He called the Web "a collaborative medium, a place where we all meet and read and write" (Laningham, 2006).

Our investigation revealed that courses using the term $\mathrm{Web} 2.0$ occurred less frequently than those specifically mentioning social media and social networking. Further, a large proportion of these courses were oriented toward directly pragmatic and developmental aspects of Web 2.0, such as programming. These findings suggest the term $\mathrm{Web} 2.0$ is used in instructional practice as an enabling technology rather than a phenomenon. It also suggests that course descriptions using this term appeared relatively early in the move to provide social media education.

Altogether, the findings indicate that a number of universities are working toward the inclusion of social media material in their curricula. While this does not definitively mean social media is here to stay, it does indicate that many universities are devoting resources to its establishment in their courses. Furthermore, they are investing in both the technology to produce it as well as the social phenomena surrounding it. As such, it behooves academics in business departments to investigate how they may best deliver this increasingly important content and consider adding their own material on the subject in the near future.

\section{Approaches to Course Development}

The remainder of this article focuses on specific courses offered at three major AACSBaccredited university business schools and the lessons learned during implementation. In all three examples AACSB mandates were put into practice using a recommended 'systematic process' for developing information systems competence in business.

Any social media course must have a sound pedagogy for its base regardless of delivery approach and underlying learning theories that provide a philosophy. Teaching method is important but 
efforts must also focus on the content. As a mechanism for accomplishing this, an approach used to develop a set of learning objectives for teaching business ethics was adopted from Kidwell, Fisher, Braun, and Swanson (2013).

Kidwell et al. (2013) suggests that learning objectives should be based upon Bloom's Taxonomy, a classificatory model in use for over 50 years in the development of curricula. Bloom's Taxonomy inherently builds more complex components upon simpler ones. This lends itself to a situation where beginning concepts can be introduced via instructivism-based pedagogy (McHaney, 2011), intermediate concepts relate to constructivism-based pedagogies (Brandt, 1997), and finally, in our case, students leave the course with a connectivist mindset (Siemens, 2005). Bloom's Taxonomy (Bloom, Engelhart, \& Furst, 1956) is well-established and has been used in numerous fields to describe how new behaviors can result through the process of learning. The Anderson, Krathwohl, Airasian, Cruikshank, Mayer, Pintrich, Raths, and Wittrock (2001) model was updated in 2001, and that version was used for this article. This taxonomy has been used in a wide variety of business education related venues (Kidwell et al., 2013). Among these are accounting (Baker, Simon, \& Bazeli, 1987), information systems (Harper \& Harder, 2009; Mohtashami \& Scher, 2000), human resources (Knight, 2013), and others (Warren, 1992).

The effective application of Bloom's Taxonomy is apparent when organizing topics and teaching pedagogies for learners exploring social media for business. By teaching fundamental concepts first, the learner becomes accustomed to the field of study and then can "develop and become integrated with other behaviors to form more complex behavior which is classified in a different way" (Bloom et al., 1956; Kidwell et al., 2013). As pointed out by Kidwell et al. (2013), the taxonomy is also well-suited for representing how pedagogies will be developed based on different learning theories. Kidwell's process included (1) identifying stages for developing subject matter competence; (2) aligning these stages with Bloom's taxonomy; and (3) developing learning objectives to support the process. We utilized a series of stages for teaching social media and Web 2.0, and for student competence development. The hierarchical nature of these five stages for developing competencies is analogous to Bloom's Taxonomy and its levels of learning. The following sections describe each of Bloom's levels in brief detail (Anderson et al., 2001):

Remembering is the ability to retrieve, recall, or recognize information that has been committed to memory. Facts, definitions, patterns, procedures, and other structured information are typically associated with this level.

Understanding is characterized by the ability to derive meaning from various forms of information. Interpretations, classifications, summaries, inferences, comparisons, and explanations are all examples of a learner being able to make use of the material in this level.

Applying is being able to use knowledge to carry out a procedure in either related or new situations. Executing, implementing, changing substantial details, and still being able to perform a task characterizes this level. Applying can be carried out using models, interviews, simulations, and other approaches.

Analyzing is being able to break the big picture into its components and then being able to determine how those components interact and interrelate. This activity includes mental actions such as organizing, attributing, and differentiating as well as distinguishing among fact, opinions, and hypotheses. Applications can use surveys, spreadsheets, diagrams, charts, or symbolic representations.

Evaluating is the process of making judgments based on criteria, prior experience and standards. Critiques, checks, inspections, recommendations, and reports are related to evaluation. These mental actions require determining value and include the capacity to compare with known standards. 
Creating, a high-level activity, involves constructing a whole from various elements. The goal here is to form a functional whole. Other related activities include reorganizing elements into new patterns, creating new structures, producing a new product or element, or inventing. Creating can involve synthesis.

In addition to levels indicated by Bloom's Taxonomy, learning, as defined by connectivist thinkers, can extend beyond the individual (Siemens, 2005). Learners become nodes on a community of networks which include people, information sources, and other resources. Individuals learn as community expertise is acquired. Connectivism empowers a community of learners and extends knowledge by proxy as participants become experts with know-where. For this reason, the modified version of Bloom's Taxonomy shows an additional level, networking, to represent connectivist-learning, natural to those working in the realm of social media

Networking moves beyond individual actions and requires activities related to connecting nodes that have been created, co-created, or discovered by the learner (Siemens, 2005). In networking learning becomes a community effort and knowledge is housed at both individual and community levels. New digital tools enabling the formation of online communities produce this higher level of learning.

Illustrating the five stages provides insight into methods for teaching in this area (Kidwell et al., 2013). Stage 1: Enhancing social media for business knowledge can be compared to the first two levels of Bloom's Taxonomy, remembering and understanding. Stage 2: Developing skills for social media for business is the first level of application where students begin to recognize that deeper aspects of the topic are present. Understanding begins to emerge. Stage 3: Improving abilities to use social media for business involves the processes of applying and analyzing. Stage 4: Maintaining an ongoing ability to acquire and create new knowledge and skills relating to social media for business requires evaluating their learning and beginning to use it in knowledge creation. Stage 5: Extending knowledge as intelligent nodes while community expertise is acquired with regard to social media and Web 2.0 for business emphasizes the need for lifelong learning and the ability to network with other knowledge creators. Social media has the ability to extend knowledge and help users to function as intelligent nodes. Community expertise is acquired with regard to subject matter, and social media enables the premise that "learning is no longer an internal, individualistic activity." Networking and information exchange are essential (Siemens, 2005). Table 2 provides Bloom's Taxonomy with an added network stage and further illustrates the stages used in course development.

Table 2: Bloom's revised taxonomy mapped to general learning objectives

\begin{tabular}{|l|r|}
\hline Stage in Bloom's Revised Taxonomy & Stages for Competence \\
\hline Remember & $1 . \quad$ Enhancing \\
\hline Understand & $1 . \quad$ Enhancing \\
\hline Apply & $2 . \quad$ Developing \\
\hline Analyze & $3 . \quad$ Improving \\
\hline Evaluate & $4 . \quad$ Maintaining \\
\hline Create & $4 . \quad$ Maintaining \\
\hline Network & $5 . \quad$ Extending \\
\hline
\end{tabular}




\section{Specific Implementation Examples}

Approaches to course development were explored further through an examination of social media courses offered by this article's authors. All three of these courses utilized approaches that followed the 'stages for competence' described in Table 2. Early material was definitional and was eventually moved into creative phases where social media use was fostered with a constructivist mindset. End goals for the courses included making sure each student possessed understanding of how to acquire information regarding social media applications through a network of nodes as a connectivist (Siemens, 2005). Details regarding the three specific classes follow.

\section{University \#1}

Example \#1, entitled Social Media, was a seven-week undergraduate course offered at a major East Coast U.S. university and was $100 \%$ online. The focus of this course was on standard Web 2.0 and Social Media topics such as blogs, wikis and podcasts, Facebook, LinkedIn and Twitter. In addition, students learned about powerful and useful Web 2.0 cloud-based tools such as Jing, Dropbox, Feedly, SoundCloud, Evernote and others. Students were challenged on issues such as privacy, whether or not social media was "good or bad" for our society, and, as Sherry Turkle (2011) put it, the new phenomenon in which we are "alone together." Three textbooks were used for the course: Web 2.0 and Social Media for Business by McHaney (2013), Social Networking $2^{\text {nd }}$ Edition by Miller (2013) and Web 2.0 Concepts and Applications by Shelly and Frydenberg (2011). Students who attended this class came from all parts of the university; they were business majors, communication majors, drama and theatre majors, nursing students, psychology majors, and others. Some of them came into the class with prior expertise in social media. When asked, they talked about their significant familiarity with Facebook, Twitter, LinkedIn, Instagram, and Pinterest. Some, however, professed a distinct ignorance of the details. They knew that social media was out there, and they thought that they should know more about it and should be using it, but were not quite sure where to start. Many expressed concerns about how it all worked or what role social media could (or should) play in their lives. The course itself has been offered twice each semester since Fall 2012 with a cap of 25 students, and it was filled immediately. Activities for the course included reading articles, watching videos, taking quizzes, submitting papers, and participating in a discussion board each week. Students had a set amount of work to do each week; they chose the timing of when to complete the work and submit their assignments, but all work was submitted on a weekly basis.

\section{University \#2}

Example \#2, entitled Web 2.0 and Social Media Management, was a 10-week (summer) graduate course offered at a major southern U.S. university and was $100 \%$ online. The focus of this course was Web 2.0 technologies, not only as course content but also as course infrastructure to increase student-to-student and professor-to-student interaction (Doring, Hodge, \& Heo, 2014). The primary topics covered were social media, online tools, social networks (including Twitter and Facebook), wikis, and blogs. Course material comprised information from the book Web 2.0: Concepts and Applications (Shelly \& Frydenberg, 2011), informative videos pertaining to social media, and other online tools, including social networks, wikis, and blogs. Students in this course were primarily business students (all majors), but also included were some Public Administration and Political Science students. Activities and assignments for the course were based both on individual and group work and utilized Web 2.0 technologies such as Google Docs and Microsoft SkyDrive (now renamed "OneDrive"). The course used social media to teach social media and added class discussion, assignments, and tests online. Instructors discussed collaboration theory and then put it into practice for a variety of projects using social media tools. Assignments included: comparing different blogs and blogging platforms; discussing the reliability of cloud computing; contrasting benefits and weaknesses of crowdsourcing; assessing whether social net- 
working is a fad or paradigm shift; viewing, analyzing, and discussing videos pertaining to Web 2.0 technologies; determining the value of social media used by political candidates and business officials; discussing mobile technologies; and evaluating the risk and threats of Web 2.0 technologies in business. Items from industry press played an important role in this course.

Researchers have pointed out that some distance courses are less effective because of the "lack of prompt feedback, ambiguous instructions on the Web, and technical problems" (Hara \& Kling, 1999). To mitigate this, the primary media used to facilitate discussion in this course were Twitter, Facebook, and a built-in university discussion board. The instructors described Twitter from a business perspective, then provided an example in class. Instructors continually informed students regarding current events and other information pertaining to the course. This provided a sense of how business could use this technology. Facebook groups provided another example of using social media to teach social media. Within this context students posted questions and created discussion topics. This approach facilitated prompt feedback from classroom peers as well as the professor and teaching assistants. This provided an invaluable way for clarifying class issues, highlighting and discussing major current events related to the use of social media in organizations, and gathering additional responses. Many students were already familiar with the organization and structure of Facebook, and this lowered the learning curve.

\section{University \#3}

Example \#3, entitled Digital Business, was a 16-week undergraduate course offered at a major Midwestern U.S. university and was hybrid with some online and some face-to-face sessions. The course focused on five major, interrelated components: social computing, social media, content sharing, filtering, and Web applications. These components were explored within the context of business application and new business development. The premise of the class was that modern business faces an emerging digital environment largely shaped by forces outside its control. Two of these forces, Web 2.0 and the arrival of tech-savvy Millennials, demand that managers and planners reconsider approaches to computing, communication, marketing, data management, accounting/finance, purchasing, selling, and nearly all other aspects of business. This course explored an emerging set of technologies without sacrificing proven business practices. Additionally, it provided students with a solid foundation for the digital environment they are likely to encounter in their future careers. This course used Web 2.0 and Social Media for Business by McHaney (2013) as the textbook. While the course was primarily intended for business students, many of those who were enrolled were from other disciplines, including computer science, engineering, human ecology, agriculture, and areas where specific business or entrepreneurial interests exist.

This course included activities that introduced students to the topics dynamically in a business context and provided practical development experience through projects, exams and assignments. Students were expected to understand and appreciate the business impact of Web 2.0 technologies including social computing, social media, content sharing, filtering/recommendations, and Web applications; to demonstrate proficiency in the use of blogs, wikis, podcasts, social tagging, and new Web 2.0 applications; to become familiar with emerging online business tools and gain proficiency in their use; and to conduct research on social media tools and their applications.

The course helped entrepreneurs and business people explore how today's consumers are different and to understand how to interact within digital environments. This course examined a number of important technologies that have converged to enable business transformation. Among these were networked computer systems, content development tools, online office suites, new application programs, and mobile smart devices. Additionally, the vast free information resources that have reshaped how knowledge is stored and communicated were examined in detail. Business use of these resources was emphasized. This course also examined information nodes which 
form the basis for personal learning networks and change the way people work and interact. Social bookmarking and tagging tools created to filter, sort, and find what is needed were explored in order to use this emerging information effectively.

\section{Quality and Student Feedback}

All three courses were well-accepted by students. Activities were treated with enthusiasm, assignments were generally completed with high quality, and student interest was high. Discussion threads were active and used frequently by students. Additionally, students provided positive feedback regarding the courses both in class evaluation forms and in personal messages in social media venues.

To illustrate, students from the example universities were asked to complete a feedback form at the end of each class in which they had the opportunity to reflect on what they had learned, what they took away from the class, and what might have made it better. Their comments and suggestions have been incorporated into future iterations of the classes. Sample comments follow.

"This is my first time using social media through this medium. Let me first comment on Flickr. It is a very creative and useful site. I couldn't believe the fact that it can allow you to store up to one terabyte of memory all for free. I am going to be using this site to back up some of my photos. It will also be great to share photos with my friends and family. I hope to print some photos with one of Flickr's affiliates. As for Delicious, at first I thought it would just be same old book marking, but I was wrong. It can be accessed from multiple devices, which makes things a lot easier. I can also find things and share them with my friends. These are very powerful tools. I just wished that I had signed up to learn about them a lot earlier as some of my peers did. Now I see what all the fuss is about. I am glad that this course exposed me to it."

"I thoroughly enjoyed this course. I thought I understood everything about the world of social media but I was wrong. It was interesting to find out more about blogs and wikis and I liked learning about Pod Cast. I always wanted to have a blog but never felt like I had time to start one, but thanks to this course I know how to effectively manage my own blog. My favorite new social media venture to use is Delicious. It will help me keep track of things that I like and wanted to read about on the web but may not have time to at the moment. It's a way to keep me from procrastinating and working more effectively."

"I am really glad I decided to take this course, especially because of my chosen field. I was really impressed with how useful some of the sites I had never used before were. I honestly didn't think there was a point to sites like Flickr and Delicious, but I find that I am still using them for personal use. I also enjoyed learning about what goes into social media sites and how they are able to connect us. I've never really thought about all that goes into making social media sites like these and how they work. I also learned new things about sites I use often like Twitter, which I can use now."

"I think this course covered everything that I was expecting, which makes me very happy. I don't think there was anything more that this course needed to make it better. I think that this class has the ability to benefit anyone. I can definitely say that it has given me a lot more confidence knowing that I am now aware and somewhat experienced with the material and social networking sites that I will most likely be using in my future. Before this course, I was not aware about almost half of the material we covered. This made me nervous because I am majoring in communications and feel that I needed to familiarize myself with the various forms of social media that are out there today. I got everything out of this course that I wanted to and I couldn't be happier that I had the opportunity to take it." 
"This course provided hands on experience in developing social media applications. I learned that Facebook is more than a way to contact my friends and family. This experience opened my eyes to what business needs to do with social media."

\section{Discussion and Implications}

Web 2.0 and social media technologies are currently transforming the business world (Kaplan \& Haenlein, 2010) and having an impact on teaching and learning. As mentioned earlier in this article, business schools will be at risk of losing relevance unless changes are made to course content, supplemental materials, and resources as technologies modernize and impact strategic approaches to conducting business. This fact was brought into clear focus following our initial investigation into approaches being used to teach social media at AASCB-accredited business schools. Our study revealed that approximately $19 \%$ of these schools had programs specifically offering social media courses. This number rose to about $22 \%$ when other related topics such as Web 2.0 were included. This represents a recognition that social media is gaining traction in business education but also indicates a great deal of work remains. We believe there may be several reasons for the low rate of implementation. First, social media is a relatively new Internet phenomenon and, if the past is an indicator, it might be viewed by some as a fad. While we do not believe this to be the case, many others might be taking a 'wait and see' approach. Another reason might be due to the fact that business school curricula often have little room for new course work. AASCB requirements are stringent and may not allow the addition of extra course work without impacting graduation timelines. Finally, based on our research, we believe there may be a question as to what department or functional area is best suited for teaching social media. As reported earlier, we found evidence of social media minors and social media courses in areas other than IS. Arguments can be made for these topics to reside in marketing, MIS, management, and other places within business and in other non-business areas such as journalism, computer science, and anthropology.

A major implication of this study was that no clear approach appeared to be the norm in teaching social media. For this reason we focused on specific courses offered at three major AACSBaccredited university business schools and investigated their implementation processes. In all three examples AACSB mandates were considered and used to guide systematic methods for enhancing information systems competence in business. The instructors from the three courses organized their collected knowledge according to 5 stages which generally correspond to levels in Bloom's Taxonomy. The stages were used to indicate which pedagogies should be considered at various points in the course implementation process. This process has been followed in curricula areas other than social media to construct approaches to offering new coursework (Anderson et al., 2001; Kidwell et al., 2013). This approach provided an organized way to scaffold learning and move students from merely recognizing terminology to being able to actively participate and contribute to smart business use of social media. A number of implications are pertinent at each stage.

Stage 1: Enhancing social media for business knowledge: Any education effort requires understanding a topic area's common language and accepted practices. The three university courses reviewed in this article engaged in remembering and understanding in a variety of forms. In all three courses examined a general set of background material was provided to the students. Although today's students have been called digital natives and many are considered tech-savvy Millennials, there is a large difference between casual technology use for friendly social interaction and technology use for business. Students required a firm base of knowledge that explained how Web 2.0 concepts emerged, what defined social media, how Web 2.0 and social media systems worked, and how technology has evolved. These concepts were offered through the use of standard textbooks, online tools like flashcards, and PowerPoint lectures. The course instructors felt 
that the students still required this background source material to provide an even footing for deeper understanding. Furthermore, understanding in the three courses was characterized by the ability to derive meaning from various forms of information. As pointed out in the example case of University \#2, industry press was a helpful application. Academic literature may be a year or more behind in terms of the latest trends due to the rapid speed of social media evolution. Basic concepts and fundamentals of social media and Web 2.0 can generally be covered academically; however, the latest trends and new product information may be difficult or impossible to locate. Use of industry press helped overcome these issues. The lack of refinement in information from these sources may be an acceptable cost in exchange for exposing students to it earlier. Indeed, the industry press often takes hard-learned, practical lessons into account, giving students anecdotal information about the proper and improper use of social media and new technologies that surround it. Students appreciated the aspect of realism and reported greater understanding regarding how social media could be used strategically and differently in business settings. In addition, the course instructors conducted discussions to help in developing a basic understanding of the topics. Students asked questions using social media, such as discussion boards, to ensure their comprehension went deeper than merely remembering.

Stage 2: Developing skills for social media for business: The three courses reviewed all enhanced student skill sets in basic social media use. The corresponding Bloom's level, applying , was implemented in these example courses by ensuring that students were able to use knowledge to carry out business-related social media tasks in new situations. This stage's activity was important to the success of the classes because it required hands-on experience using social media software, models, simulations, and other approaches. It was certainly true that some students came into these classes being familiar with one or more social media platforms such as Facebook, Twitter, or Instagram. However, students still had much to learn about business applications and other social media areas that they did not regularly use, such as LinkedIn. Instructors in the three courses reported that familiarity with common tools did not instantly translate into more sophisticated expertise. The basis for using social media was substantially different. For example, sending out Tweets on a personal account is vastly different from developing a social media strategy and then carrying out a directed campaign using multiple, coordinated tools. Additionally, another implication of teaching in the 'applying' area is that both students and instructors needed to be aware that no guarantee exists for any particular social media tool to remain dominant indefinitely. Consequently, we found it important that coursework emphasized tool diversity in order to gain a better understanding of social media systems in general as opposed to mastery of one or two platforms that may become obsolete with the rapid changes in technology. This also helped prevent students from over-familiarizing themselves with one company's systems to the extent that they become inflexible.

Stage 3: Improving abilities to use social media for business. After mastering basic tool use, analyzing business needs through a social media lens helped students step back from using specific tools and look at functions from a strategic standpoint. During this stage students began to move into deeper learning as they broke the big picture into components and then determined how those components interacted and interrelated. We found that an instructor should encourage students to analyze various social media tool functions and select the appropriate application to achieve a particular business goal. Using this approach gave the instructors a sense that application of a variety of tools through usage is a key element of any social media course. Technical support can put analyzing into practice. We found this was a role that instructors ended up playing whether they wished to or not. Myriad new technologies made support and debugging applications a time consuming activity. We encouraged students to use existing online community resources to help analyze problems and to interact through message boards and other online forums. We found this helped develop analysis skills. It was also helpful to us as instructors to expect to provide help and offer "fast start" tutorials. In some cases we had to work with the university's IT support de- 
partment in order to determine where and when to refer students to helpdesks and other campus resources. Additionally, the incorporation of social media use for help functions can be used to motivate participation, facilitate collaboration, and provide prompt feedback. Information from the three courses reviewed for this article revealed that students were highly motivated to use social media for projects and course work completion and to help their peers. Some students who had never used these technologies previously realized the benefit they could bring to other aspects of their lives and careers. As educators increasingly turn to social media to communicate with their students (Moran, Seaman, \& Tinti-Kane, 2011), the benefits of its use in teaching become more salient, and, as such, it is important to introduce its utility through instruction and example.

Stage 4: Maintaining an ongoing ability to acquire and create new knowledge and skills relating to social media for business. There is no doubt that social media will continue to change. It became important in all three example classes to enhance student abilities to update and maintain their skills. The Bloom's level of evaluating focuses on the process of making judgments based on criteria, prior experience and standards. Students in the three university courses completed critiques, checks, inspections, recommendations, and reports to better understand how social media was being used effectively in business settings. Among items used by instructors in this area were tools for measuring social buzz such as social mention, mention.net and Klout.com. These tools were used to evaluate the effectiveness of social media campaigns. Students were required to determine value of social buzz and developed benchmarks to compare outcomes with actions taken (e.g., retweets, media mentions, and positive reviews). An implication noticed during the evaluation level was that the very nature of social media courses made them susceptible to a potential pitfall - an inherent instability as a learning platform. New technologies are developed all the time, particularly as Web site integration becomes more complete. Many unanticipated permutations became possible, even for novices (e.g., Facebook apps, rule changes, and various browser extensions). Many of technologies were found to be applicable to social media or directly connected to major social media services. We believe it imperative that a social media instructor not be enamored with the plethora of options but rather pay attention to the strategic implementation of social media and then understand whether goals were achieved. Covering too many technologies meant only a few could be covered well. An additional complication was that instructional materials have a very short shelf-life, becoming obsolete quickly. We found one way to provide both breadth and depth to these social media courses was to encourage students to conduct evaluations of available tools in a particular category and then focus on a particular one for in-depth application. Online learning resources such as MOOCs, tutorials, and so forth were used to keep skills up-to-date.

Additionally, this stage (Bloom's level of creating) involved constructing a social media campaign from various elements. All three example courses included elements where the goal was to form a functional whole. General activities included understanding the social media environment then using new knowledge to reorganize elements into new patterns. For example, students created blogs, then sent out related tweets through Facebook business pages. In other instances they constructed online articles, websites, or rolled out embedded widgets. Additionally, creating can involve synthesis from a variety of social media platforms. In all three courses students suggested that working through social media development projects helped them acquire new capabilities or improve existing abilities.

Stage 5: Extending knowledge as intelligent nodes while community expertise is acquired with regard to social media and Web 2.0 for business. Information resides in networks. One implication for this new reality is that learning has begun to move beyond individual actions. Students had to find ways to connect to nodes that were created, co-created, or discovered by themselves or their peers. The consequences were far-reaching and opened new venues for acquiring knowledge. For instance, the goal became preparing students for post-classroom success where 
they would need to find reliable information in their domain areas. New digital tools assisted the formation of online communities and enabled this higher level of learning. Students found online forums, discovered better ways to search for reliable information, and learned how sharing resources could lead to better outcomes. Web sites such as SlideShare, DocStoc, Flickr, Wikipedia, and others were used to illustrate the concept of self-regulating communities and their value to business. This level was relevant and needed in a social media environment even though it is not part of Bloom's taxonomy (Siemens, 2005). The central premise of networking was extending knowledge as intelligent nodes while community expertise was acquired. Students experienced, joined, and contributed to communities of practice using the processes described in this article. This enabled them to understand how knowledge can be housed outside the individual according to connectivist ideas and helped them become part of the knowledge infrastructure developing across the globe. This doesn't mean that traditional communication should not be used. In fact, coursework such as this often required a step back into traditional technology.

Social media platforms, including Facebook, Twitter, LinkedIn, Flickr, YouTube, Instagram, Pinterest, and numerous others, have begun to revolutionize the way businesses view customers, clients, potential clients, employees, external stakeholders, and others (Dunlap \& Lowenthal, 2009). In fact Web 2.0 concepts and social media have transformed Internet use from an informational platform into a communication and interaction platform. Business schools cannot afford to ignore the vast changes these technologies have brought and must use a combination of learning theory applications, skills, knowledge, and expertise to prepare students for the future (Roebuck, Siha, \& Bell, 2013). Table 3 summarizes takeaways for each stage in the process of making this happen.

Table 3: Key Takeaways from Stages for Teaching Social Media

\begin{tabular}{|l|l|l|}
\hline \multicolumn{1}{|c|}{ Stage } & \multicolumn{1}{|c|}{ Key Activities } & \multicolumn{1}{c|}{ Key Social Media Technologies } \\
\hline $\begin{array}{l}\text { Stage 1: Enhancing } \\
\text { social media for busi- } \\
\text { ness knowledge }\end{array}$ & $\begin{array}{l}\text { Learning required back- } \\
\text { ground. }\end{array}$ & $\begin{array}{l}\text { Online resources; Textbooks; Websites; } \\
\text { Wikipedia; PowerPoint; Online Lectures; } \\
\text { E-Flashcards; E-Books }\end{array}$ \\
\hline $\begin{array}{l}\text { Stage 2: Developing } \\
\text { skills for social media } \\
\text { for business }\end{array}$ & $\begin{array}{l}\text { Using social media } \\
\text { tools. }\end{array}$ & $\begin{array}{l}\text { Twitter; Facebook; LinkedIn; Blogs; } \\
\text { Websites; Instagram; YouTube; Other } \\
\text { social media sites }\end{array}$ \\
\hline $\begin{array}{l}\text { Stage 3: Improving } \\
\text { abilities to use social } \\
\text { media for business }\end{array}$ & $\begin{array}{l}\text { Integrating and using } \\
\text { social media for busi- } \\
\text { ness purposes. }\end{array}$ & $\begin{array}{l}\text { Social media campaigns consisting of } \\
\text { combinations of tools such as Blogs, Fa- } \\
\text { cebook Business Pages; LinkedIn Busi- } \\
\text { ness Features; Review Sites; Media Sites }\end{array}$ \\
\hline $\begin{array}{l}\text { Stage 4: Maintaining } \\
\text { an ongoing ability to } \\
\text { acquire and create } \\
\text { new knowledge and } \\
\text { skills relating to social } \\
\text { media for business }\end{array}$ & $\begin{array}{l}\text { Learning how to acquire } \\
\text { social media skills as } \\
\text { tools change, and how to } \\
\text { create online artifacts. }\end{array}$ & $\begin{array}{l}\text { Online learning resources; MOOCs; Tuto- } \\
\text { rials; Klout; mention.net; New apps }\end{array}$ \\
\hline $\begin{array}{l}\text { Stage 5: Extending } \\
\text { knowledge as intelli- } \\
\text { gent nodes while } \\
\text { community expertise is } \\
\text { acquired with regard } \\
\text { to social media and } \\
\text { Web 2.0 for business }\end{array}$ & $\begin{array}{l}\text { Learning how to become } \\
\text { an active part of the } \\
\text { growing information } \\
\text { infrastructure. }\end{array}$ & $\begin{array}{l}\text { Flickr; DocStoc; SlideShare; Animoto; } \\
\text { GoAnimate; Camtasia; Other tools that } \\
\text { permit sharing of resources }\end{array}$ \\
\hline
\end{tabular}




\section{Conclusion}

This study provides a strong recommendation that business schools offer social media courses. This recommendation is informed by two primary sources. First, business practices are altering the way they connect with customers and other stakeholders through social media implementations. This change is dramatic and rapid as more companies incorporate related goals into their strategic planning and use tools provided by vendors such as Facebook, LinkedIn, Twitter, WordPress, and others. Second, Standard 15 of the AACSB (2013) suggests a systematic process for curriculum management which covers skill areas such as the use of information technology that "influence[s] the structure and processes of organizations and economies and influence[s] the roles and techniques of management." The authors believe the current impacts of social media and Web 2.0 technologies certainly meet this criteria and must be considered in future curriculum updates. There is little doubt that the adoption of social media tools has completely altered communication strategies for industries, government, individuals, and universities. Technologies such as Facebook, Twitter, YouTube, and Google+ can be incorporated effectively or ineffectively into these environments. In the corporate world correct usage of these services may lead to product promotion or brand name recognition, whereas incorrect usage may lead to a damaged name and reputation. Although businesses are embracing these technologies ( $71 \%$ of large corporations), only $22 \%$ of AACSB accredited schools of business are teaching the topic and only $39 \%$ are incorporating their own use of social media due to concerns related to bandwidth drain, security or privacy intrusion, extraordinary expense to support, or lack of benefits (Case \& King, 2011).

Our primary goal for this article was to provide both motivating factors and practical implementation suggestions for teaching social media in a business school. To accomplish this we first provided a sense of how many business schools were offering coursework in the area of social media. During that phase of our study we found not many AACSB-accredited business programs appeared to be offering social media courses. Specifically, only $19.23 \%$ had programs with social media content. This number improved slightly more if the criteria was broadened to include related topics $(22 \%)$. This low number indicates much work remains to be done. Second, we offered a methodology for creating new social media courses using the experience and best practices of three implementations. Background information was collected through a review of three specific university courses that effectively applied Bloom's Taxonomy to organize topics and teaching pedagogies for learners engaged in exploring social media in business. The idea that complex learning was constructed from simpler components was illustrated through an adaptation of Kidwell's course development process (Kidwell et al., 2013) which included (1) identifying stages for developing subject matter competence; (2) aligning these stages with Bloom's taxonomy; and (3) developing learning objectives to support the process. Similarly to Kidwell, we utilized a series of stages for teaching social media analogous to Bloom's Taxonomy and added a level representing connectivist thinking which characterized new media and online social networking. This illustrated the concept that learning can extend beyond the individual (Siemens, 2005). We believe that teaching social networking effectively requires that learners become nodes in a community and extend their knowledge by proxy as participants become experts with know-where. The stages illustrated in our recommended course development were informed by three example courses currently offered at AACSB-accredited universities.

\section{Limitations and Future Directions}

This study has its limitations. For instance, when researching college catalogs for evidence of social media courses and programs, we could use only publically accessible material. A publication delay often exists as new courses are trialed and added to the formal listing later. Additionally we provided a detailed analysis of 3 social media courses at major universities. This is in no way exhaustive nor the only possible approache to teaching in this area. Other alternatives exist 
which could be explored in more detail in future studies. Likewise, our adaptation of Kidwell et al. (2013) was useful for our AACSB-accredited universities but may not apply equally well to universities with different learning objectives and criteria. Even with these limitations, the current study provides insight on social media courses and teaching in business colleges. Since there is limited research regarding this topic, we feel that this study contributes to the literature in this area.

Educators and scholars alike would benefit from additional work examining social media as both a tool and a subject of study. Examining the relationship of social media and its use by other majors/departments would extend this study. As described earlier, a variety of programs outside of IT-oriented disciplines embrace social media in their subject matter. Investigations into these trends may help understand the linkage between social media and other disciplines. Examining its spread would also provide an interesting example of a technology that can be used as a teaching tool in itself, helping to understand both the instruction of IS subjects as well as the adoption of a prolific IS artifact.

Evaluating learning content acceptance with models such as the Content Acceptance Model (Barelka, Jeyaraj, \& Walinski, 2013) may help provide a more thorough understanding of related phenomena to encourage students to embrace online education and aid online educators in engaging their pupils. Additionally, surveying instructors directly to see how they view and use social media and whether they include it in their courses may illuminate current practical uses of social media in education as well as its status as a subject of instruction. Such a study may also provide further benefit by allowing for comparative studies among faculty members in different departments. Better understanding of social media users in both business and education can provide further insights useful to adding elements to business curricula and aligning these with course learning objectives. Additional study is also needed to empirically test how the network element derived from connectivist theory aligns with levels of learning in Bloom's Taxonomy. Supporting theory for this area has not been fully developed.

\section{Summary and Recommendations}

In spite of this study's limitations, we believe social media is a necessary topic in business schools. Its benefits certainly outweigh any uncertainties. Additionally, using social media to teach social media is beneficial as it increases collaboration and awareness among students and faculty in a number of ways. Since prior research has suggested no significant difference exists in learning between distance education and traditional face-to-face approaches (Tucker, 2001; Wagner, Garippo, \& Lovaas, 2011) and since online learning is gaining momentum (Dykman \& Davis, 2008), we found social media facilitated the collaboration among geographically dispersed students (Ralph \& Ralph, 2013). We believe social use of new media tools exposed our students to new capabilities and promoted interpersonal communication. Adding a business focus to this knowledge resulted in improved abilities and new venues for personal development. Instructors ensured that students left the courses with adaptable knowledge that allowed them to maintain new skills as well as acquire/create new insights. Other lessons-learned are summarized by category:

Course Projects: Students suggested that working through social media development projects helped them acquire new capabilities and improved existing abilities. It enabled them to see social media from a different and more professional perspective. The idea of developing social media use policies and thinking about the ramifications of sending out messages made a deep impression. Additionally, social use of tools promoted interpersonal communication aspects of classroom learning. Likewise, students were motivated to experience, join, and contribute to communities of practice and learning. Projects in the area of knowledge creation helped most students recognize how learning can become a lifelong asset. 
Curriculum Development: Curriculum resources in this area are developing but not mature. Instructors of the exampled three courses used a variety of textbooks and other material and noted that course material has an extremely short shelf life. This makes industry press a valuable resource. Fundamentals are covered in the literature and in textbooks, while industry press can add realism and currency to a course. The instructors of the examined courses spent considerable time developing custom course material. A critical lesson was that it is important to select what to teach with care; poor choices decrease instructional value.

Students: Although students have been called digital natives and may be tech-savvy, a knowledge chasm existed between causal technology use for friendly social interaction and technology use for business. Likewise, students may already have been very familiar with one or more applications but few had used all tools in sophisticated ways. That being said, most class participants enjoyed using social media and were highly motivated to learn new tools and techniques. Another important comment by an instructor was to remember to stay involved with the class, support the students, and remain in contact with them through social media.

Teacher Concerns: Among issues mentioned by instructors of the exampled courses was a lack of time. This was particularly true in distance learning venues. A lack of face-to-face communication and ways to ensure undivided student attention led to participant procrastination as well as thrown-together or highly-unbalanced collaborative projects. Instructor involvement in the course work and using techniques such as requiring regular status reports helped mitigate this problem to some degree. Instructors also suggested that if you try to teach everything, nothing will be taught well. Do not assume that "rapidly evolving" technology can be set up in a short time, especially when relying on many disconnected individuals. Do not without warning make changes midsemester to incorporate new technology.

Teaching Techniques: Instructors and students often learned together since the course work included exploring new tools. The idea of co-learning emerged and provided an excellent venue where the enthusiasm and experience of students could be tempered and mentored into relevant business space by the instructors. In other examples, social media worked well as both a teaching tool and subject. For instance, a class Twitter feed demonstrated useful communication features that would translate directly to the business world. Other helpful teaching advice included that instructors found networking via telephone contact provided a sense of comfort and value, particularly for less advanced students in online course sections. Media Richness Theory (Daft \& Lengel, 1984) may describe why engaging in real-time voice communication with students added a level of concreteness to the course. Other forms of real-time communication, such as the use of chat services, were also beneficial in this regard. Another strategy that worked well was to hold an introductory, on-campus "class meeting" so students and instructors familiarized themselves with one another to some extent. However, not all students were able to attend, and instructors had to plan for this, with class members joining the meeting with real-time video (e.g., Skype). In a similar way, it is worth holding online "study sessions" with built-in chat facilities to connect instructors and students. Furthermore, this offered an advantage that traditional lectures do not in the form of logged conversations for future reference.

Tools and Online Resources: Potential challenges to teaching social media come from the very medium itself. This is particularly true if distance learning delivery is being used. For instance, several students did not have a Facebook account. They were concerned about privacy or a lack of security. Some did not want to share their account details with the class or instructor. In one of the courses examined, much of the discourse occurred on Facebook, causing discord in the discussion-participation component of the class. Another drawback was that many online tools simply disappeared. For instance, in one of the courses, a tool called Stickam was being used, and it simply ceased operation on a particular day with little warning. So, there is no guarantee that any social media tool or platform will remain viable (or free) indefinitely. Social media companies as 
well as specific tools may disappear or be purchased and absorbed into another entity. The number of websites and tools used in the course must be carefully balanced to avoid over-complexity. Students should be exposed to more than one tool or type of social media but must also not be overwhelmed through the use of too many tools and websites. Instructors suggested not jumping on brand new, possibly transitory, technology at the expense of core concepts. Instead, use care not to be too rigid to add new developments to a course.

Training Activities: It is important to recognize that teaching social media has an inherent pitfall the rapid evolution of its own technology. This means continual training is required and exercises developed for students need to be validated frequently. For this reason it becomes imperative that a social media instructor not get too carried away with the large number of available tool options. It is important to prevent students from over-familiarizing themselves with a tool to the extent that they become inflexible. Related to training, technical support was a role often taken on by instructors. We found that additional support may be necessary. University helpdesk services may help minimize problems in this area.

Taken in sum, this article provided both motivating factors and practical implementation suggestions for teaching social media in a business school. We believe our initial research examined how businesses are strategically using social media and provided an impetus for creating new courses. Further, the three examples of how major universities are approaching the current, broad technology changes sweeping through social and business milieus provided additional insight. The process of implementing these changes included offering courses that teach social media theory and application through the use of various Web 2.0 and social media platforms as described in the discussion. Bloom's Taxonomy adapted through Kidwell's, et al. (2013) example provided a framework for structuring learning. Likewise, this article promoted the idea of developing classroom experiences that provide lasting value through scaffolding for lifelong learning experiences. Students are able to form personal learning networks and become part of fast-paced, changing networks of information. Students and faculty continue to learn as community expertise is acquired and participants become experts with know-where (Siemens, 2005, p. 1). The development and delivery of new social media courses can achieve success with attention to the lessonslearned provided in this article.

\section{References}

AACSB. (2013). Business accreditation standards. Retrieved from http://www.aacsb.edu/accreditation/business/standards/aol/standard15.asp

Aburdene, P. (2005). Megatrends 2010: The rise of conscious capitalism. Hampton Roads Publishing.

Anderson, L. W., Krathwohl, D. R., Airasian, P. W., Cruikshank, K. A., Mayer, R. E., \& Pintrich, P. R. (2001). A taxonomy for learning, teaching, and assessing: A revision of Bloom 's taxonomy of educational objectives. New York: Longman.

Bahner, D. P., Adkins, E., Patel, N., Donley, C., Nage, R., \& Kman, N. E. (2012). How we use social media to supplement a novel curriculum in medical education. Medical Teacher, 34(6), 439-444.

Baker, R. E., Simon, J. R., \& Bazeli, F. P. (1987). Selecting instructional design for introductory accounting based on the experiential learning model. Journal of Accounting Education, 5(2), 207-226.

Barelka, A. J., Jeyaraj, A., \& Walinski, R. G. (2013). Content acceptance model and new media technologies. Journal of Computer Information Systems, 53(3), 56-64.

Berners-Lee, T., Cailliau, R., Luotonen, A., Nielsen, H., \& Secret, A. (1994). The world-wide web. Communications of the ACM, 37(8), 76-82.

Bloom, B. S., Engelhart, M. D., \& Furst, E. J. (1956). Taxonomy of educational objectives: The classification of educational goals. Handbook 1: Cognitive domain. New York: David McKay. 
Brandt, D. (1997). Constructivism: Teaching for understanding of the internet. Communications of the $A C M, 40(10), 112-117$.

Brightman, H. J., \& Nargundkar, S. (2013). Implementing comprehensive teacher training in business doctoral programs. Decision Sciences Journal of Innovative Education, 11(4), 297-304.

Buzzard, C., Crittenden, V. L., Crittenden, W. F., \& McCarty, P. (2011). The use of digital technologies in the classroom: A teaching and learning perspective. Journal of Marketing Education, 33(2), 131-139.

Buzzetto-More, N. A. (2012). Social networking in undergraduate education. Interdisciplinary Journal of Information, Knowledge, and Management, 7, 63-90. Retrieved from http://www.ijikm.org/Volume7/IJIKMv7p063-090Buzzetto611.pdf

Case, C. J., \& King, D. L. (2011). AACSB accredited institutions and the Web 2.0: Lagging behind businesses in social networking implementation. Issues in Information Systems, 12(2), 1-8.

Chao, J. T., Parker, K. R., \& Fontana, A. (2011). Developing an interactive social media based learning environment. Issues in Informing Science and Information Technology, 8, 323-334.

Daft, R. L., \& Lengel, R. H. (1984). Information richness: A new approach to managerial and organizational design. Research in Organizational Behavior, 6, 191-233.

Deans, P. C. (2012). Integration of study abroad with social media technologies and decision-making applications. Decision Sciences Journal of Innovative Education, 10(3), 299-336.

Doring, A., Hodge, A., \& Heo, M. (2014). Online learners and their self-disclosure preferences. Journal of Information Technology Education: Research, 13, 163-175.

Duggan, M., \& Brenner, J. (2013). The demographics of social media users - 2012. Retrieved from http://pewinternet.org/Reports/2013/Social-media-users.aspx

Dunlap, J. C., \& Lowenthal, P. R. (2009). Tweeting the night away: Using Twitter to enhance social presence. Journal of Information Systems Education, 20(2), 129-135.

Dykman, C. A., \& Davis, C. K. (2008). Part one - The shift toward online education. Journal of Information Systems Education, 19(1), 11-16.

Halvorson, W., Crittenden, V. L., \& Pitt, L. (2011). Teaching cases in a virtual environment: When the traditional case classroom is problematic. Decision Sciences Journal of Innovative Education, 9(3), 485-492.

Hanna, R., Rohm, A., \& Crittenden, V. L. (2011). We're all connected: The power of the social media ecosystem. Business Horizons, 54(3), 265-273.

Hara, N., \& Kling, R. (1999). Students' frustrations with a web-based distance education course. Retrieved from http://firstmonday.org/htbin/cgiwrap/bin/ojs/index.php/fm/article/view/710/620

Harper, J. S., \& Harder, J. T. (2009). Assurance of learning in the MIS program. Decision Sciences Journal of Innovative Education, 7(2), 489-504.

Harris, A. L., \& Rea, A. (2009). Web 2.0 and virtual world technologies: A growing impact on IS education. Journal of Information Systems Education, 20(2), 137-145.

Hrastinski, S., \& Aghaee, N. M. (2012). How are campus students using social media to support their studies? An explorative interview study. Education and Information Technologies, 17(4), 451-464.

Huhman, H. (2013). How to manage tech-savvy millennials. Retrieved from http://www.womenpoweringbusiness.com/how-to-manage-tech-savvy-millennials/

Jeffrey, L., Hegarty, B., Kelly, O., Penman, M., Coburn, D., \& McDonald, J. (2011). Developing digital information literacy in higher education: Obstacles and supports. Journal of Information Technology Education: Research, 10, 383-413. Retrieved from http://www.jite.org/documents/Vol10/JITEv10p383-413Jeffrey1019.pdf 
Junco, R. (2012). The relationship between frequency of Facebook use, participation in Facebook activities, and student engagement. Computers \& Education, 58(1), 162-171.

Junco, R. (2013). Inequalities in Facebook use. Computers in Human Behavior, 29(6), 2328-2336.

Kaplan, A. M., \& Haenlein, M. (2010). Users of the world, unite! The challenges and opportunities of social media. Business Horizons, 53, 59-68.

Kelm, O. R. (2011). Social media: It's what students do. Business Communication Quarterly, 74(4), 505520.

Kidwell, L. A., Fisher, D. G., Braun, R. L., \& Swanson, D. (2013). Developing learning objectives for accounting ethics using Bloom's taxonomy. Accounting Education, 22(1), 44-65.

Kietzmann, J. H., Hermkens, K., McCarthy, I. P., \& Silvestre, B. S. (2011). Social media? Get serious! Understanding the functional building blocks of social media. Business Horizons, 54(3), 241-251.

Knight, E. M. J. (2013). Aligning the curriculum of the human resources management undergraduate courses at an English speaking university in the Carribean with the university's 2012-2017 strategic plan. Global Business and Economics Research Journal, 2(8), 61-86.

Laningham, S. (2006). DeveloperWorks interviews: Tim Berners-Lee. Retrieved from http://www.ibm.com/developerworks/podcast/dwi/cm-int082206txt.html

Lee, J. S. (2008). Status of business process courses in AACSB-accredited undergraduate programs of business. Journal of Computer Information Systems, 49(1), 10-16.

Levy, M., \& Hadar, I. (2010). Teaching MBA students the use of Web 2.0: The knowledge management perspective. Journal of Information Systems Education, 21(1), 55-67.

Magro, M. J., Sharp, J. H., Ryan, K., \& Ryan, S. D. (2013). Investigating ways to use Facebook at the university level: A Delphi study. Issues in Informing Science and Information Technology, 10, 295311.

McAfee, A. (2006). Enterprise 2.0: The dawn of emergent collaboration. MIT Sloan Management Review, 47(3), 21-28.

McHaney, R. (2011). The new digital shoreline: How Web 2.0 and millennials are revolutionizing higher education. Herndon, VA: Stylus Publishing.

McHaney, R. (2013). Web 2.0 and social media for business (2nd ed.). Copenhagen: Ventus/Bookboon.com.

Miller, M. (2013). Social networking (2nd ed.). Upper Saddle River, NJ: Prentice Hall.

Mohtashami, M., \& Scher, J. M. (2000). Application of Bloom's cognitive domain taxonomy to database design. In Proceedings of ISECON (Information Systems Educators Conference).

Moran, M., Seaman, J., \& Tinti-Kane, H. (2011). Teaching, learning and sharing: How today's higher education faculty use social media (pp. 1-26). Pearson Learning Solutions.

Morgan, L. (2012). Generation Y, learner autonomy and the potential of Web 2.0 tools for language learning and teaching. Campus-Wide Information Systems, 29(3), 166-176.

Nielsen Company. (2012). State of the media: The social media report. Retrieved from http://www.nielsen.com/content/dam/corporate/us/en/reports-downloads/2012-Reports/The-SocialMedia-Report-2012.pdf

O'Reilly, T. (2005). What is Web 2.0: Design patterns and business models for the next generation of software. Retrieved from http://www.oreilly.com/pub/a/web2/archive/what-is-web-20.html?page=1

Ralph, M., \& Ralph, L. (2013). Weapons of mass instruction: The creative use of social media in improving pedagogy. Issues in Informing Science and Information Technology, 10, 449-460. 
Roebuck, D. B., Siha, S., \& Bell, R. L. (2013). Faculty usage of social sedia and mobile devices: analysis of advantages and concerns. Interdisciplinary Journal of E-Learning and Learning Objects, 9, 171192. Retrieved from http://www.ijello.org/Volume9/IJELLOv9p171-192Roebuck0859.pdf

Sacks, M. A., \& Graves, N. (2012). How many "friends" do you need? Teaching students how to network using social media. Business Communication Quarterly, 75(1), 80-88.

Shelly, G. B., \& Frydenberg, M. (2011). Web 2.0: Concepts and applications. Boston, MA: Course Technology.

Shim, J. P., Dekleva, S., Guo, C., \& Mittleman, D. (2011). Twitter, Google, iPhone/iPad, and Facebook (TGIF) and smart technology environments: How well do educators communicate with students via TGIF? Communications of AIS, 29(35), 657-672.

Siemens, G. (2005). Connectivism: A learning theory for the digital age. International Journal of Instructional Technology and Distance Learning, 2(1), 3-10.

Sulčič, V., \& Lesjak, D. (2009). E-learning and study effectiveness. Journal of Computer Information Systems, 49(3), 40-47.

Thomas, M., \& Thomas, H. (2012). Using new social media and Web 2.0 technologies in business school teaching and learning. Journal of Management Development, 31(4), 358-367.

Thoms, B. (2012). Student perceptions of microblogging: Integrating Twitter with blogging to support learning and interaction. Journal of Information Technology Education: Innovations in Practice, 11, 179-197. Retrieved from http://www.jite.org/documents/Vol11/JITEv11IIPp179-197Thoms1109.pdf

Tucker, S. (2001). Distance education: Better, worse, or as good as traditional education? Online Journal of Distance Learning Administration, 4(4). Retrieved from http://www.westga.edu/ distance/ojdla/winter44/tucker44.html

Turkle, S. (2011). Alone together: Why we expect more from technology. New York, NY: Basic Books.

Wagner, S. C., Garippo, S. J., \& Lovaas, P. (2011). A longitudinal comparison of online versus traditional instruction. MERLOT Journal of Online Learning and Teaching, 7(1), 68-73.

Warren, H. B. (1992). Implementing holistic education in marketing courses. Marketing Education Review, $2,21-24$.

\section{Biographies}

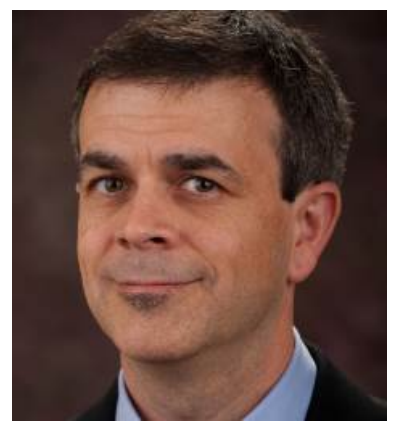

Roger McHaney is a University Distinguished Teaching Scholar and the Daniel D. Burke Chair for Exceptional Faculty in the College of Business at Kansas State University. His primary research focus has been on computer simulation and on technology use in education, and has appeared in Decision Sciences, Communications of the ACM, International Journal of Operations \& Production Management, Information \& Management, Decision Support Systems, Simulation, and others. He is author of the book The New Digital Shoreline and gives frequents talks about the impact of new media on higher education. 

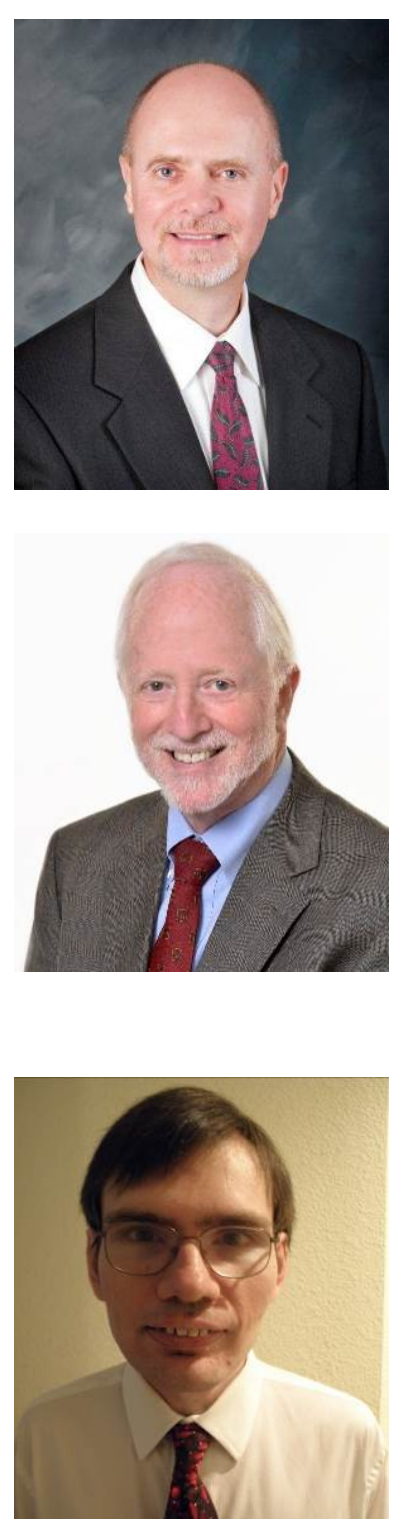

Michael Brian Pope recently earned his Ph.D. in MIS at Mississippi State University. He also holds a bachelor's and master's degree in computer science from California State University, Sacramento. His current research interests include telecommunication, security, social media, knowledge management, and the legal aspects of IS. His work has been published in Communications of the Association for Information Systems, International Journal of Wireless Networks and Broadband Technologies, and in the Proceedings of the Decision Sciences Institute annual conference, where it was nominated for best paper.

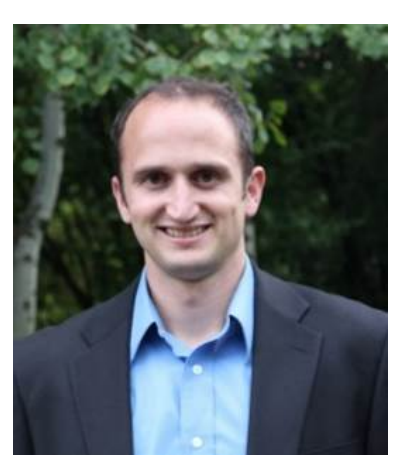

Dustin Ormond is an Assistant Professor of Business Intelligence and Analytics at Creighton University. He earned his Ph.D. in MIS at Mississippi State University. His current research interests include information security and privacy, affective computing, fraud, deception, and social media communication. He has published research in Computers \& Security, in the Journal of Computer Information Systems, in the Proceedings of the Decision Sciences Institute annual conference, and in the Proceedings of Americas Conference on Information Systems. 